\title{
ALGUNAS NOTAS SOBRE LA RESTAURACIÓN DE LA PUERTA DE LOS APÓSTOLES DE LA CATEDRAL DE VALENCIA. (ESPAÑA)
}

\author{
(SOME REMARKS ABOUT THE RESTORATION OF THE APOSTLES DOOR \\ OF THE CATHEDRAL OF VALENCIA. SPAIN)
}

Julián Esteban Chapapría, Dr. Arquitecto

Fecha de recepción: 4-VIII-93

Jefe del Servicio de Patrimonio Arquitectónico de la Generalitat Valenciana.

$128-48$

\section{RESUMEN}

La puerta de los Apóstoles de la Catedral de Valencia, edificada en la primera mitad del s. XIV, constituye uno de los ejemplos más sobresalientes de las portadas

monumentales del gótico meridional. La intervención realizada fue fruto de un convenio de mecenazgo entre empresas e instituciones, $y$ destinada a ejecutar obras de conservación sobre la fábrica, degradada por el mal funcionamiento constructivo, y las esculturas, reponiendo mediante réplicas las de los apóstoles retiradas hace treinta años.

Un conjunto de operaciones constructivas, desde el vaciado de la terraza del falso triforio a retacados y reintegraciones, fueron la base para proceder a fases de limpieza y consolidación del soporte de piedra $y$ pátinas. Fueron incorporadas instalaciones especiales como una barrera antihumedad y un sistema para alejamiento de palomas, que evitará que aniden $y$ que depositer sus excrementos.

\section{SUMMARY}

The Apostle door of the Cathedral of Valencia, Built in the first half of the 14th c., is one of most extraordinary examples of the monumental main fronts of southem Gothic. The intervention carried out was fruit of an agreement of sponsorship among companies and institutions and was aimed at realizing conservation work on the masonry, degraded by poor building functioning, and the sculptures, replacing by replicas those of apostles removed thirty years ago.

Various construction operations, such as emptying the terrace of the false triforium, reintegrations and compression filling were the basis on which it was proceeded to the stages of cleaning and consolidation of the stone and patina base. Special installations, such as anti-humidity barrier and a pigeon repellent system, which wil avoid their nest building, have been incorporated.
En noviembre de 1992, y tras dieciocho meses de trabajos, finalizaban una serie de tareas encaminadas a la conservación y puesta en valor de la Puerta de los Apóstoles de la Catedral de Valencia. Esta intervención surgió como fruto de la colaboración entre diversas instituciones y empresas para restaurar uno de los elementos arquitectónicos más emblemáticos de los valencianos, tanto por su arquitectura como por ser el lugar de celebración del Tribunal de las Aguas, que además se emplaza en uno de los paisajes urbanos de mayor centralidad de la "Ciutat Vella".

El arquitecto Arturo Zaragozá ha comparado la Catedral de Valencia, iniciada en 1262, a uno de esos tejidos llamados patchwork, constituido por fragmentos de telas diversas y valiosas pero de incomprensible relación. Efectivamente, su archivo testimonia cómo cada generación se propuso rehacer o ampliar el edificio conforme a nuevos ideales formales; estos testimonios permiten identificar en la materialidad de las fábricas una serie de inconclusas intenciones arquitectónicas cuyo resultado es historia todavía viva de la ciudad.

Es aventurado e incluso lleva a erróneas interpretaciones atribuir a Nicolás de Ancona, por entonces Magister Operis de la Catedral, la construcción de una "francesa" Puerta de los Apóstoles, desvinculada 


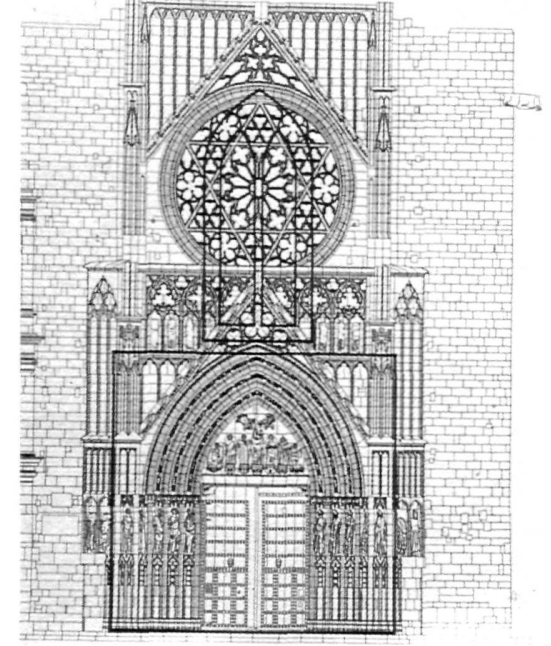

Superposición de la bipótesis de la primitiva puerta del lado del evangelio del crucero (s. XIII) con la actual Puerta de los Apóstoles (s. XIV).

de las escasas portadas monumentales del gótico catalán. En la primera mitad del s. XIV se produce la llegada a la Corona de Aragón de un buen número de maestros franco-borgoñones que participarán en la construcción de diversas obras introduciendo las maneras del gótico francés, y a uno de estos talleres parece deberse la construcción de la puerta. Pero la valenciana no alcanza la audacia constructiva del gótico borgoñón, en primer lugar porque se trata de la puerta de un transepto, y en segundo porque se halla superpuesta a una fábrica anterior con la limitación preexistente de la altura de las bóvedas, como se hace evidente en la difícil conjunción del cuerpo bajo con el rosetón. Sin embargo las características formales, en ornamentación y programa iconográfi-

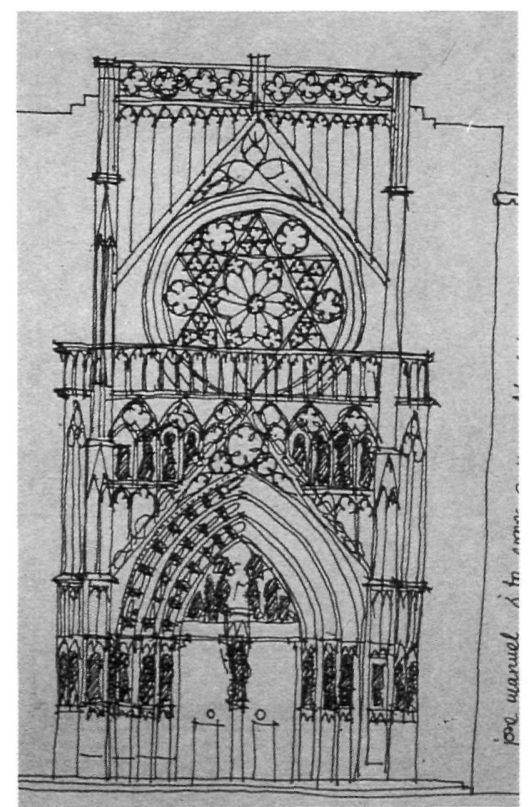

Croquis de la Puerta de los Apóstoles con hipótesis de antepechos de los dos cuerpos y parteluz original del vano principal. co, son absolutamente coincidentes con los repertorios franceses.

La investigación documental ha permitido comprobar como, durante dos siglos a partir de su construcción, las limpiezas y repintes sobre la Puerta e imágenes principales eran trabajos habituales. Pero a finales del mismo s. XIV comienzan las transformaciones de su arquitectura, primero con la colocación de unas nuevas puertas de madera, encargadas por el Cabildo con motivo de la boda de Felipe III en abril de 1599, y unos meses después eliminándose el parteluz central donde estaba la Virgen, recolocándola entre los ángeles del tímpano. Esta operación fue muy compleja debiendo desmontarse el tímpano para crear el nuevo dintel recto, y colocando las figuras sobre nuevas peanas.

Declarada monumento la Catedral de Valencia en 1931, las restauraciones llegarían tarde a ella; la primera en 1957 y precisamente a la Puerta de los Apóstoles, donde el arquitecto Alejandro Ferrant sustituyó la tracería del rosetón ya que presentaba un alto grado de descomposición. En 1967 el mismo Ferrant con Joan Segura de Lago comenzaron una fuerte intervención renovadora sobre la arquitectura de la Puerta, la cual fue absolutamente incomprendida y generó una agria polémica, agravada por el hecho de la retirada hasta hoy de los apóstoles y momos del falso triforio. Con el tiempo esta intervención quedó como un mal recuerdo siempre presente, aunque matizado por las sí admiradas y todavía más fuertes restauraciones que se simultanearon sobre el interior de la Catedral a partir de 1970.

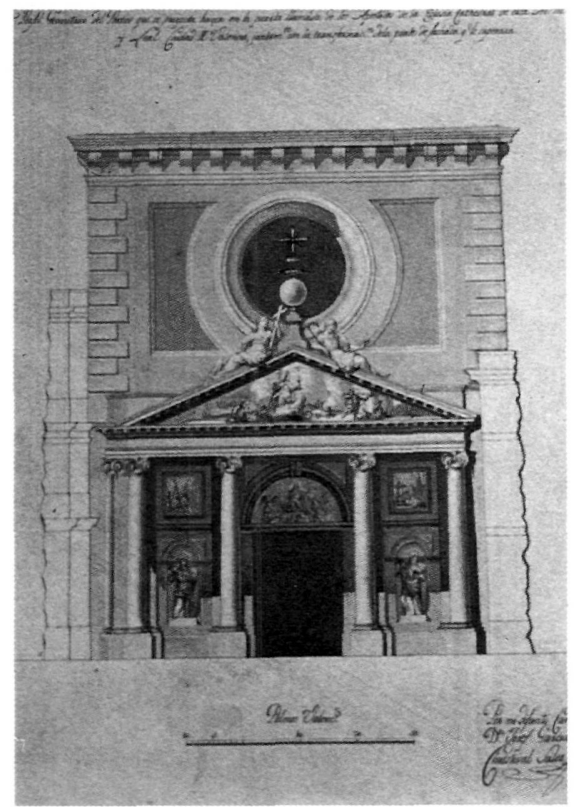

Proyecto neoclásico del arquitecto Josef García para renovar la Puerta de los Apóstoles. 
La asignatura pendiente de las desaparecidas esculturas, las pérdidas volumétricas en molduración impidiendo su adecuado funcionamiento constructivo, las patologías debidas a las lluvias y humedades, los graves problemas creados por el anidamiento de palomas, un acelerado proceso de arenización y descomposición de la pátina original en el cuerpo bajo, la fisuración y descomposición de la piedra renovada hacía treinta años, problemas de humedad de capilaridad provenientes de la pavimentación de la plaza, etc. estaban conduciendo de nuevo a la Puerta a una lenta pero inexorable degradación.

Son muchos los aspectos que la restauración de un elemento como éste aborda, al tiempo que supone una oportunidad de conocimiento excepcional por los medios auxiliares de los que se dispone y las facilidades de acceso a una información no siempre al alcance. Desde las reflexiones iniciales a la memoria final, toda una compleja trama de tareas y estudios sectoriales se han ido desarrollando, pero por motivos de extensión sólo es posible hacer referencia a algunos aspectos de especial relevancia.

Sobre una documentación gráfica inicial fue elaborada, cuando los andamios estuvieron montados, una cuidadosa planimetría de base que, vertida en ordenadores, ha permitido incorporar unas exhaustivas tomas de datos acumulando informaciones superpuestas (sillerías renovadas en otras restauraciones, hipótesis de estados anteriores, signos lapicidas, operaciones constructivas y tratamientos, evolución de mediciones, instalaciones especiales, etc.) que poste-

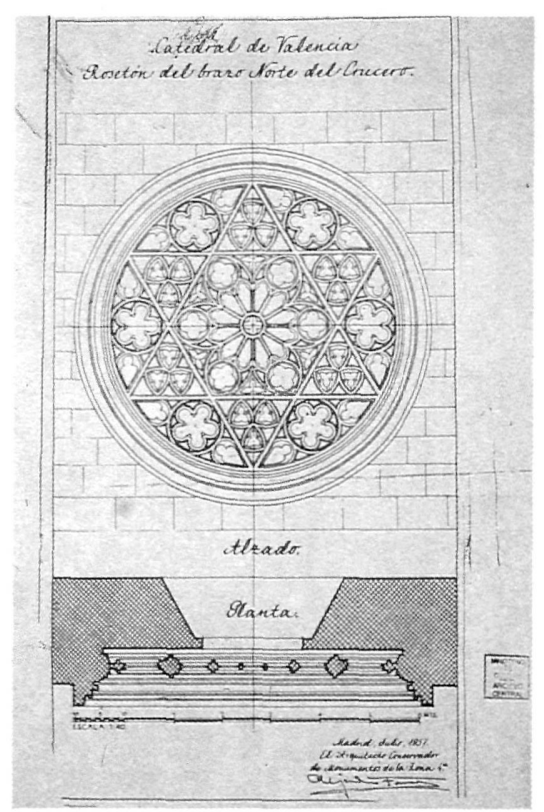

Proyecto de restauración del rosetón realizado en 1957 por el arquitecto de zona del Ministerio de Cultura Alejandro Ferrant.

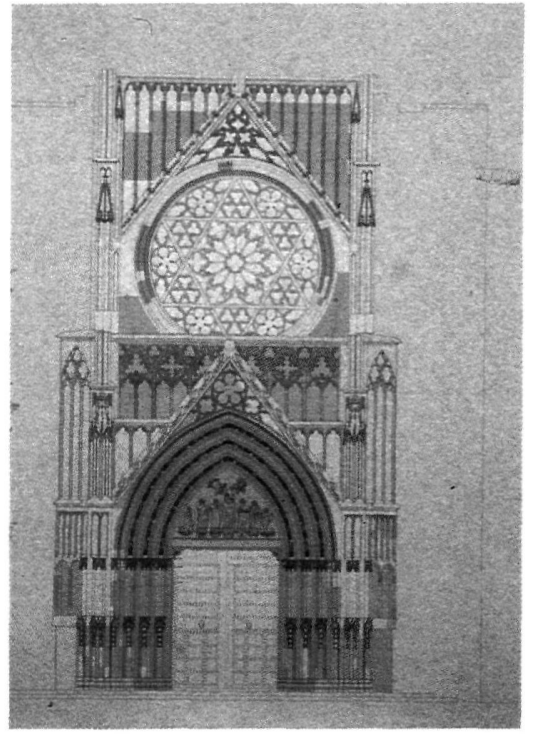

Mapeado de las zonas originales (en oscuro) y de las zonas renovadas tras la intervención de Ferrant y Segura de Lago.

riormente pueden ser solicitadas y reproducidas a la escala y combinación que se requiera. Por otro lado fueron confeccionados una serie de estudios previos destinados a conocer tanto las patologías existentes como las respuestas a posibles tratamientos de limpieza o consolidación, y a recibir asesoramiento sobre la intervención de reposición y réplicas de los apóstoles. Y de manera sustancial durante el proceso de intervención se realizó un estudio documental y análisis estilístico e iconográfico, elaborados por primera vez con carácter monográfico, ya que la información hasta entonces disponible estaba contemplada como un capítulo más de la Catedral.

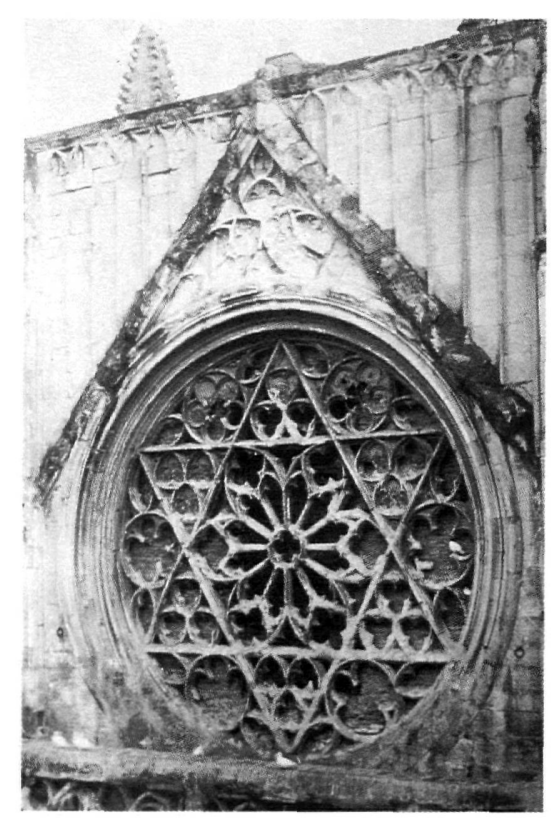

Estado de deterioro del cuerpo alto y cegado por el revestimiento neoclásico del interior, previa a la intervención de A. Ferrant. 


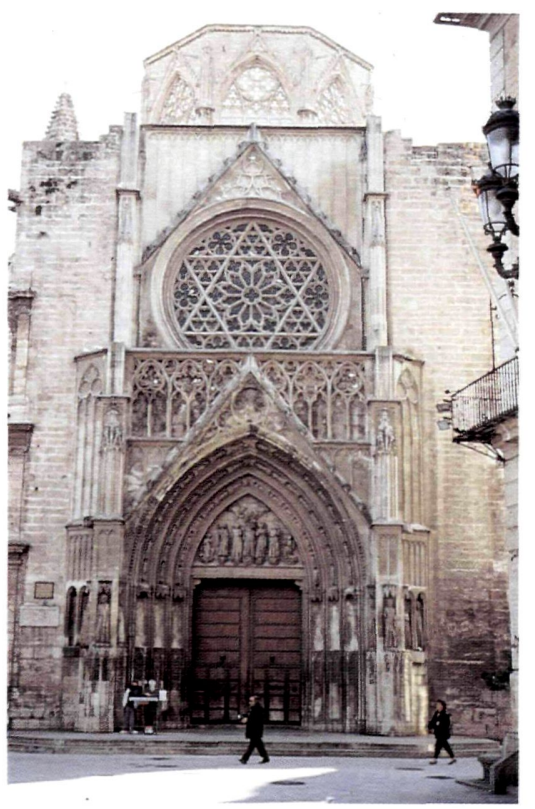

Vista general de la Puerta de los Apóstoles previa a la actual intervención. Se observa la ausencia de los grupos escultóricos del falso triforio y de los apóstoles.

El andamio de servicio instalado permitió disponer de cómodas plataformas de trabajo cada dos centros de altura, y fue cubierto por un cerramiento ligero que reproducía algunas líneas de la Puerta, ante el que siguió reuniéndose el Tribunal de las Aguas durante la obra. En el tramo final fue sustituido por mallas individualizadas en cada plataforma que permitían ser desplazadas para observar los niveles de entonación. Fue por otro lado de gran ayuda disponer, con acceso directo desde el andamio, de la Llotjeta dels Canonges y utilizarla como taller de trabajo y almacén.

Pero el grueso de los trabajos puede ser explicado desde dos amplios capítulos de obra: el de las operaciones constructivas y el de los tratamientos de la piedra. Dentro del primero pueden inscribirse un conjunto de intervenciones de microcirujía constructiva, por su intención y maneras practicadas en la terraza superior, rosetón, terraza del triforio, puerta y pavimentos, así como puntuales reposiciones de piedra, y nivelaciones y reintegraciones con mortero.

Del segundo de los grandes capítulos de obra, el de los tratamientos de la piedra, realizados con técnicas diferentes según se tratara de los laterales de piedra franca o de los cuerpos alto y bajo de la piedra ornamental, se han practicado operaciones de preconsolidación, limpieza química y mecánica, sellado y retacado de juntas, consolidación, restauración de policromías, entonación y protección final.

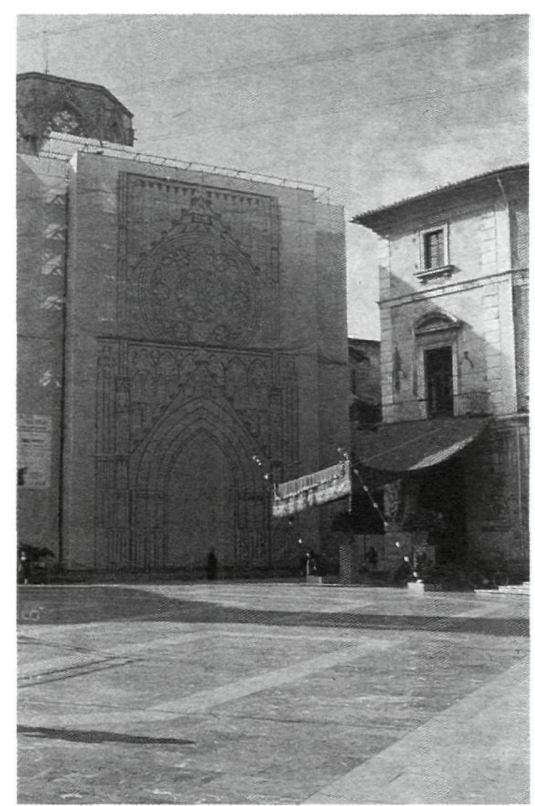

Cerramiento ligero con una abstracción de los rasgos generales de la Puerta de los Apóstoles, cubriendo los andamiajes de trabajo.

Mención aparte requiere la actuación sobre las esculturas de la Puerta, momos, tímpano y apóstoles. Los momos, llamados así por su forma irreconocible y que se encontraban en la Llotjeta en pésimo estado y con grandes pérdidas volumétricas, fueron limpiados, consolidados y reinstalados en sus emplazamientos primitivos. La Virgen y los ángeles soñadores, situados en el tímpano y por tanto más a resguardo de la climatología pero más atacados por las palomas, fueron restaurados mostrando sus distintas capas polícromas.

Sobre los apóstoles la problemática era bien diversa. En primer lugar debe decirse que hace quince años algunos de ellos fueron restaurados y replicados en el Instituto de Restauración del Ministerio de Cultura, y recolocados en la Puerta. Los originales se custodiaban en el Museo de la Catedral, y faltaban por reproducir precisamente los de ubicación más interior o protegida, que conservaban mejor los restos de policromías. Además de los doce apóstoles y cuatro santos que flanqueaban la Puerta, el apóstol del contrafuerte derecho ya no aparece en las fotografías del siglo pasado, y el del contrafuerte izquierdo se encontraba con los momos en un alto estado de degradación.

La alternativa posible respecto a la vuelta de los Apóstoles a la portada era la siguiente: desde el punto de vista de unicidad con el resto de piezas originales, autenticidad de la obra de arte y deuda social de la intervención, lo más aconsejable era reponer 


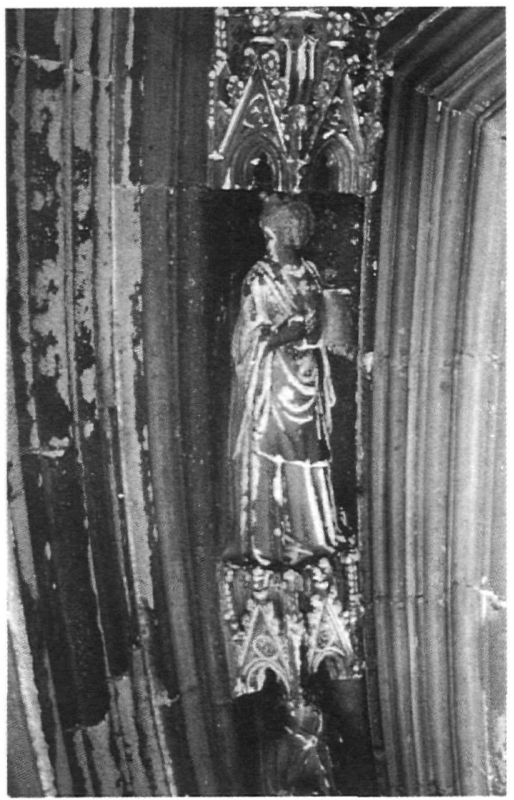

Estado de arenización, pérdida de pátina y descomposición volumétrica de las arquivoltas del cuerpo bajo, previos a la actual intervención.

todos los originales en su emplazamiento, haciendo por prudencia perfectas réplicas. Desde el punto de vista de la seguridad de los originales de los apóstoles y la conservación de su policromía, tras escuchar diversas opiniones que certificaban el grave riesgo al que se les iba a someter y a la más que probable alteración de los estucos y pinturas, debían reponerse las copias y guardar los originales. Esta última opción fue la definitivamente adoptada, calibrando además que la reposición de originales era perfecta-

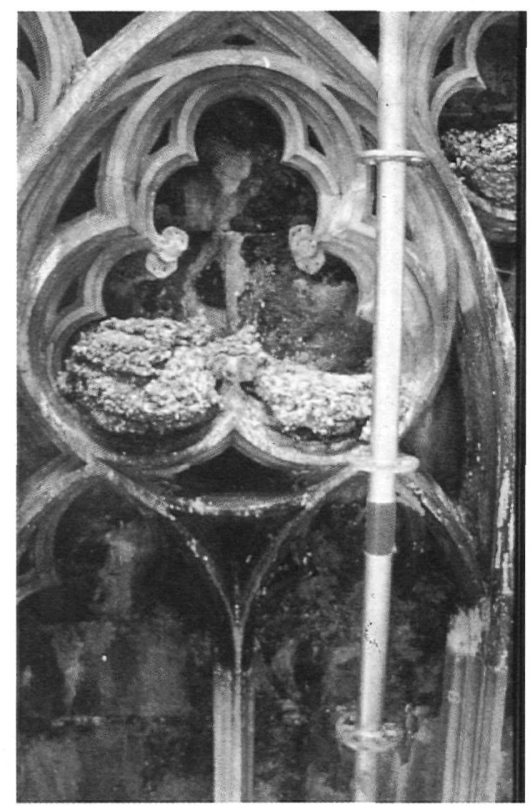

Acumulación de defecaciones de las palomas creando zonas de asiento y anidamiento permanentes. Estos restos orgánicos facilitan la aparición de bongos, ataques de ácidos y mal funcionamiento de elementos constructivos.

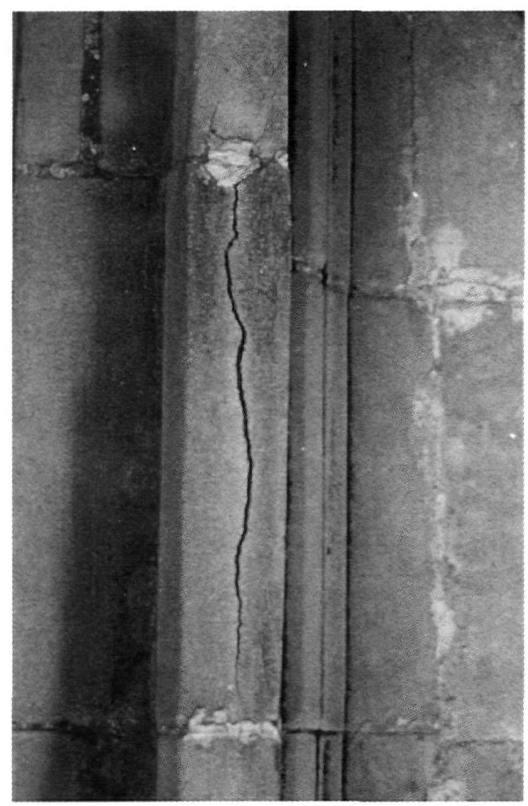

Detalle de fisuración y pérdida de morteros en juntas, en zonas ya restauradas por el arquitecto Segura de Lago.

mente posible en el momento que se deseara, dada la fácil reversibilidad de la operación.

De las operaciones constructivas realizadas únicamente voy a reseñar una de las más delicadas y de mayor implicación en la concepción inicial de la Puerta, se trata del vaciado de la terraza existente entre el cuerpo bajo y el alto tras el falso triforio. Constructivamente este macizo se realiza en origen para ganar el cuerpo necesario donde desarrollar el derrame de la puerta y las arquivoltas, pero este volumen es innecesario en el cuerpo alto donde el plano se retira para albergar el rosetón. El adelantamiento del cuerpo bajo se resuelve en superficie con una terraza que canaliza las aguas por dentro del

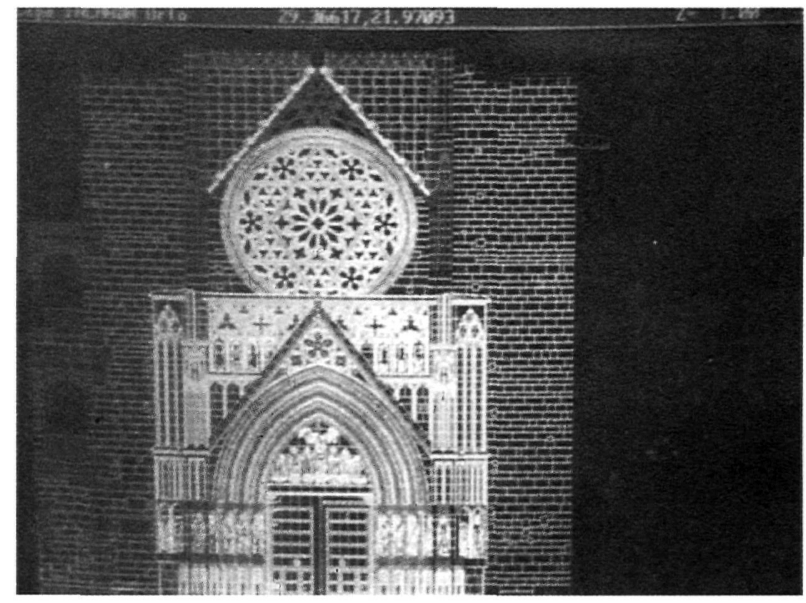

Diseño por ordenador (programa autocad V.11) de la geometría de la Puerta, superponiendo en capas múltiples informaciones principales y auxiliares 


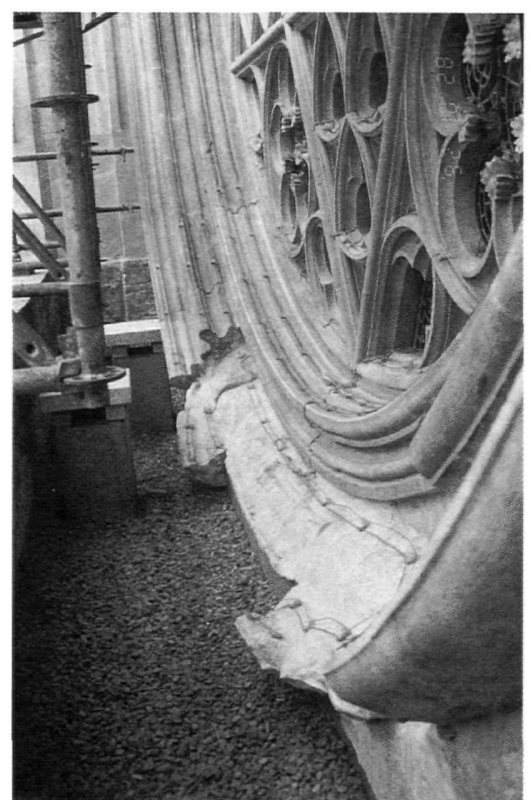

Acabado final de la terraza entre los cuerpos alto y bajo, con las chimeneas de ventilación de la nueva cámara

macizo hasta las gárgolas colocadas tres metros más abajo. El mal funcionamiento de esta terraza, por obturación de los imbornales y desagües por excrementos o cadáveres de palomas, convertían regularmente la terraza en una piscina que sólo podía eliminar el agua o por evaporación o por filtración hasta las caras inferiores, bien del falso triforio o bien de las arquivoltas, produciendo costras, arenas y pérdidas de superficie y pátina.

Los trabajos comenzaron por el levantamiento de la terraza y vaciado inicial de parte del relleno, hasta salvar el círculo exterior completo del "Salomó" y dejando al descubierto su moldura original inferior. Se pudo comprobar que se trataba de un relleno inerte y compacto, realizado en origen a base de un hormigón de cal y mampuestos, y que por lo tanto

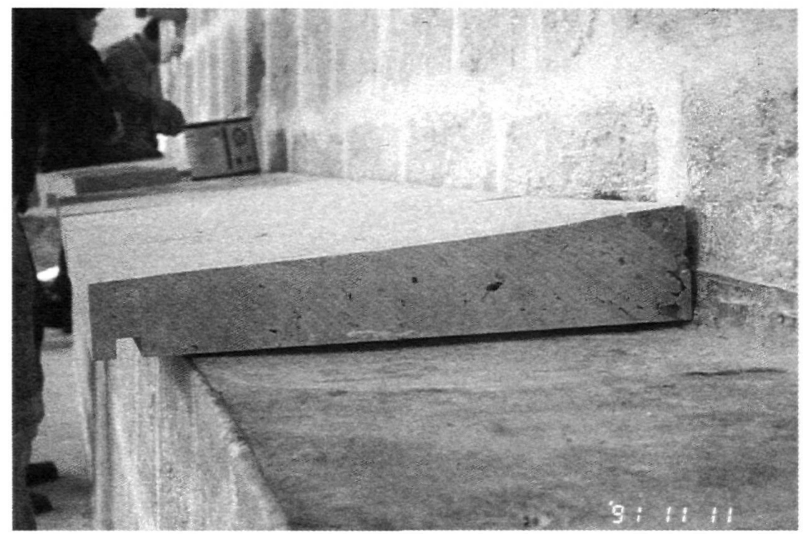

Dotación de elementos constructivos de remate y protección en la parte superior de la Puerta, recayente a la terraza del crucero.

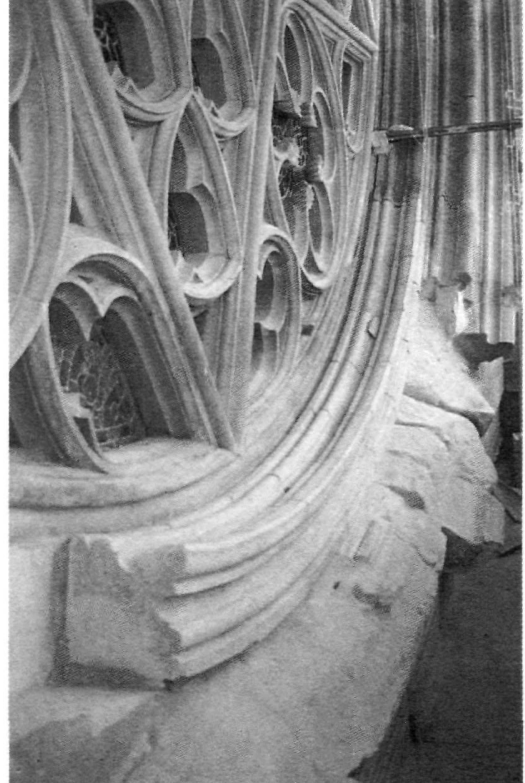

Terminación con sillares de piedra caliza del anillo interior del rosetón, dejado sin terminar en la restauración de 1957.

negaba la hipótesis un tanto ilógica de un triforio calado de acceso imposible. Por otro lado se observó cómo el muro del cuerpo alto había sido doblado en sillería para albergar el rosetón, y en el muro interior aparecían los restos del finestral correspondiente a la puerta primitiva.

La enorme masa de relleno, que ocupaba desde la terraza hasta las arquivoltas, y tenía en algunos de sus puntos una altura superior a los tres metros, tras un fallido intento de desecación fue definitivamente eliminada y convertida en una cámara ventilada por tres chimeneas, cubierta por arquillos de ladrillo tendidos transversalmente desde el muro del cuerpo alto hasta la cara interna del falso triforio, sobre los que se apoyaba el entabicado, impermeabilizante y capa final de grava.

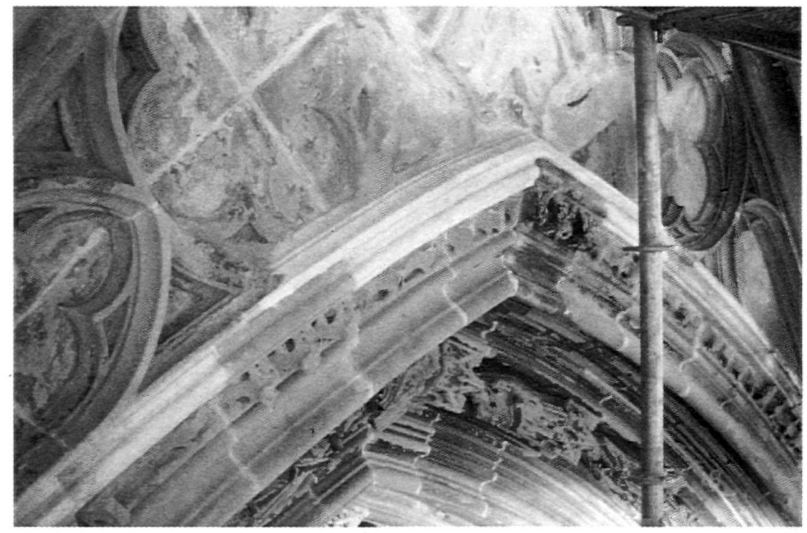

Reintegración con piedra caliza de la cornisa vierteaguas de protección de las arquivoltas. 


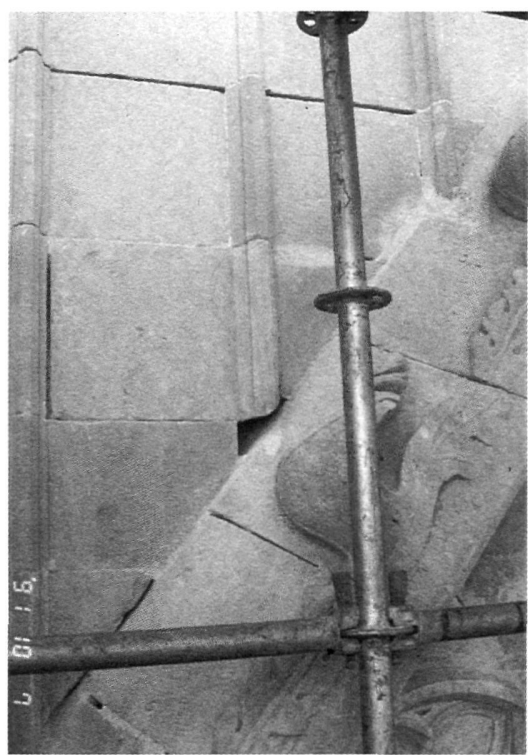

Proceso de eliminación de morteros degradados en juntas y elementos añadidos del cuerpo superior, para su tratamiento.

Respecto a los distintos tratamientos efectuados sobre la piedra, y aunque sea entrar muy superficialmente en esta cuestión, fueron especialmente delicadas las actuaciones sobre las arquivoltas. Su estado inicial presentaba una suciedad generalizada, rotura y peligro de desprendimiento de una de las pequeñas figuras, y en las zonas más exteriores pérdidas superficiales de pátina y una descomposición avanzada en forma de arena debida a la acción de los agentes climáticos y de la humedad de la piedra.

Las operaciones practicadas partían de una preconsolidación previa con un éster orgánico modificado con ácido sicílico diluido; una limpieza con una mezcla de alcohol, amoníaco y agua desionizada, excepto en zonas con fuerte carga de humedad que requerían un proceso de ayuda de secado mediante calor con infrarrojos y ventilación mecánica, la aplicación de papeletas absorbentes compuestas de celulosa, arcillas, un tensoactivo y agua, permitió la eliminación de sales afloradas en algunos puntos; y se procedió al saneado de juntas y eliminación de morteros degradados en ellas, para volver a sellar y retacar éstas con un mortero a base de resina epoxídica, cemento blanco, cal, marmolina y arena de sílice.

Uno de los procesos más delicados que se abordó fue el de la entonación, pero a este respecto la cuestión era en principio más de orden conceptual que técnico; se trataba de decidir si se debía dotar a la piedra ornamental de un revestimiento a base de tie-

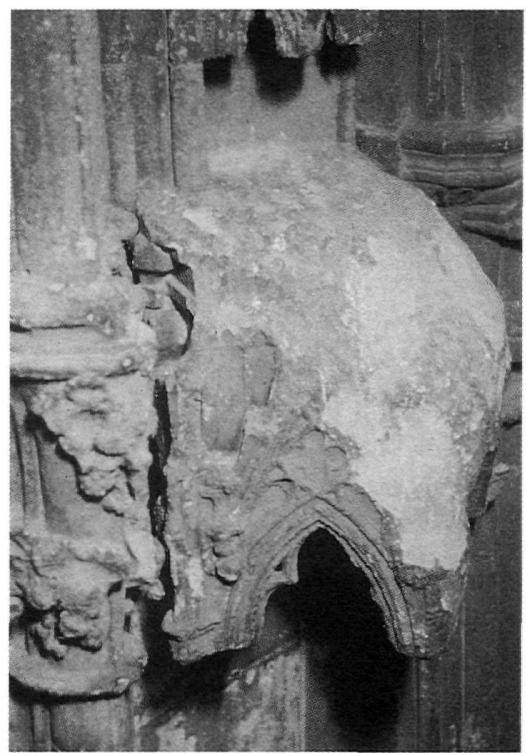

Estado de degradación, previo a la actual intervención, de uno de los doseles protectores de las esculturas de los Apóstoles.

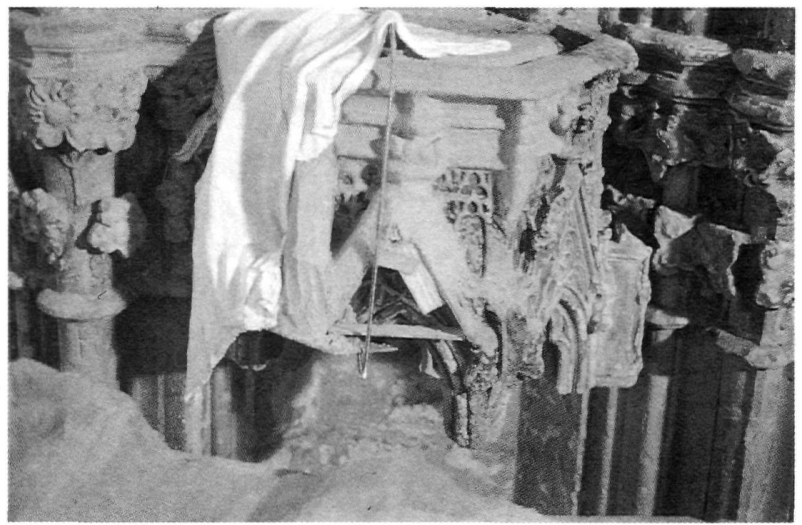

Reintegración mediante morteros y armadura de varillas de fibra de vidrio de un dosel protector de apóstol. Los morteros se mantienen tapados para conservar el grado de bumedad conveniente hasta ser objeto de la labra final.

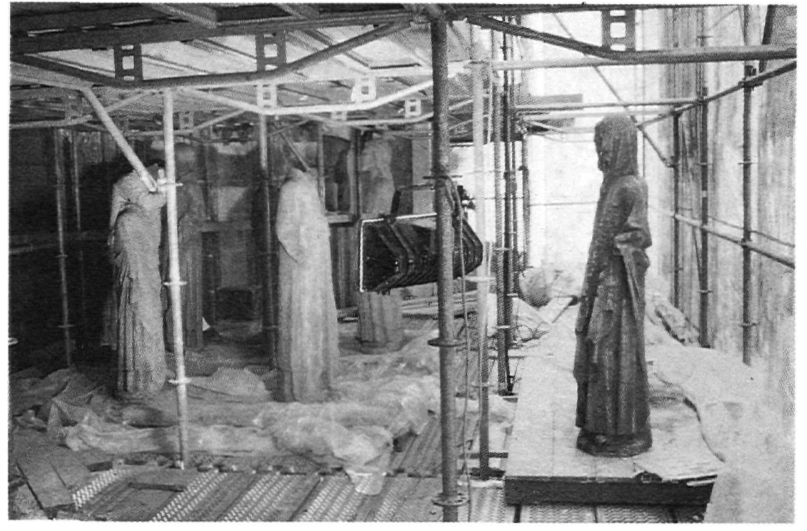

Réplicas de las esculturas de los apóstoles pendientes de su instalación definitiva. 


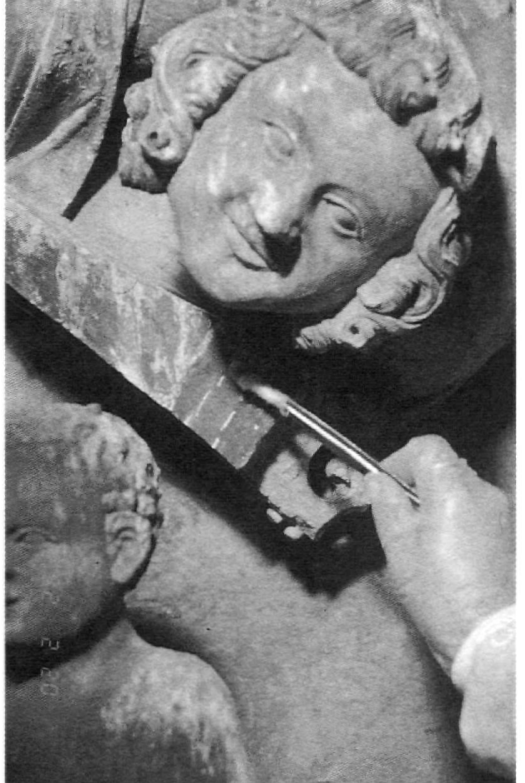

Proceso de limpieza quimica progresiva en uno de los ángeles sonadores del timpano del cuerpo bajo.

rras que, a modo de pátina, actuara tanto de protector como de teñido de la base, suturando a la vez los puntos en los que el ornamento se había perdido por la degradación ambiental; la respuesta estaba en la propia Puerta, y descarnar la pátina hasta encontrar la piedra parece hoy una práctica absolutamente rechazable. La entonación fue pues realizada con tierras naturales disueltas en un medio volátil como la acetona, que permite una penetración profunda en el poro, y tuvo una laboriosa ejecución de hacer y rehacer hasta alcanzar los niveles deseados a partir de la referencia de la arquivolta más interior que guardaba la coloración más inalterada de la protección inicial.

Por último y en el conjunto de operaciones realizadas me gustaría señalar tres instalaciones especiales, de diferente orden y finalidad, con las que se ha dotado a la Puerta.

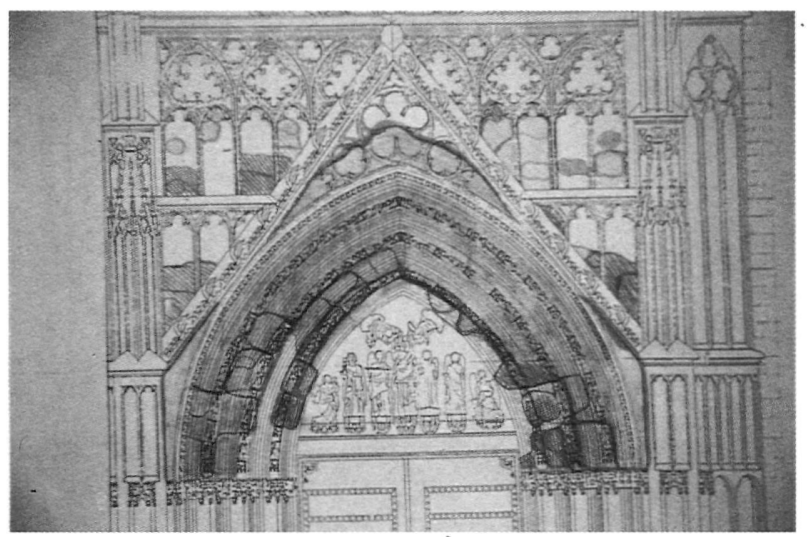

Seguimiento de la evolución de bumedad en la zona de arquivoltas, proveniente de la terraza del cuerpo bajo tras el falso triforio.

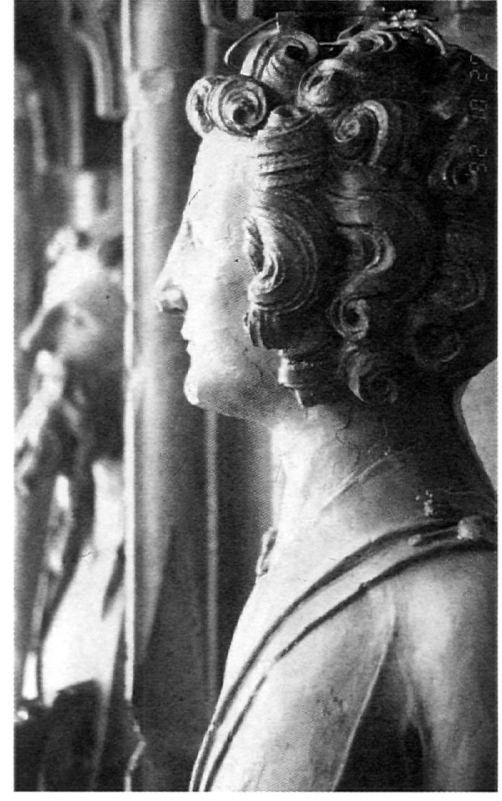

Detalle de la réplica del apóstol San Juan, ya instalado y con la policromía y patinado finales.

La primera de ellas ha sido una barrera antibumedad mediante un tratamiento de electro-osmosis pasiva y electrofóresis, destinada a conseguir una adecuada desecación de la zona inferior e impedir el ascenso de la humedad por capilaridad. El tratamiento ha sido realizado en el perímetro interior y exterior de la puerta mediante la instalación de electrodos murales y colocación de tomas de tierra, posteriormente ha sido aplicado el líquido y mortero de foresis en las perforaciones de los electrodos, e instalado las cajas de conexión necesarias, el electrodo de control y las conexiones de los terminales.

Las mediciones últimas han proporcionado unos parámetros aceptables en cuanto a la estabilización de la humedad de capilaridad. Esta instalación ha sido sellada y repasadas las alteraciones superficiales de los revestimientos, tanto en el interior de la Catedral como en los paramentos de la piedra franca y pavimentos.

La segunda de las instalaciones especiales realizadas ha sido referente a la iluminación ambiental de la Portada, dado el nivel de penumbra en el que quedaba cuando oscurecía, al encontrarse en un extremo de la plaza al inicio de una calle no muy iluminada. La iluminación proyectada y ejecutada, tras numerosas pruebas regulando temperatura e intensidad de la luz, ha consistido en regular tres operaciones simultáneamente: un baño intenso desde el interior hacia el rosetón con halogenuros metálicos, una iluminación ambiental de carácter general sobre toda la puerta mezclando halogenuros y yodocuarzo, y una focalización sectorial más intensa hacia tímpano y apóstoles con halogenuros y vapor de sodio. 


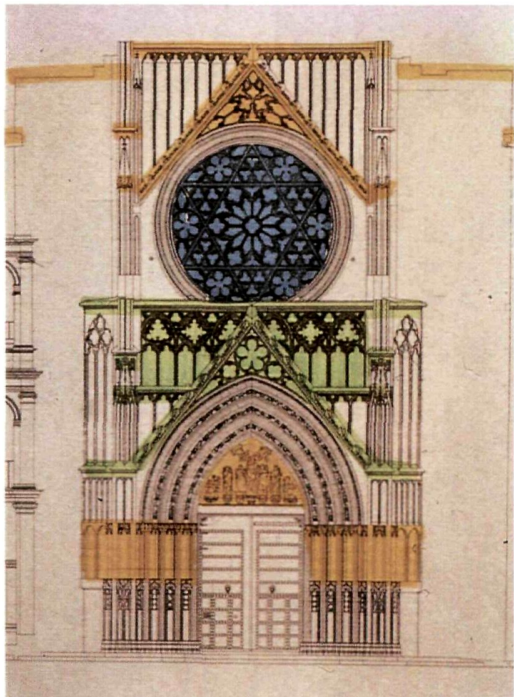

Zonas que indican la distribución de los cuatro circuitos de la instalación electrostática para el alejamiento de palomas, conectados a un único generador de impulsos.

La instalación electrostática para el alojamiento de palomas ha sido la tercera y quizá la más especial de las instalaciones realizadas. Es conocida la gravedad del deterioro y degradación que el anidamiento y asentamiento permanente de palomas provoca en los monumentos, tanto por las reacciones químicas provenientes de sus excrementos como la alteración funcional de determinados elementos constructivos, especialmente oclusión de bajantes pluviales. La acidez normal de los excrementos de las palomas causan una sensible degradación de los materiales pétreos, que se ve acentuada por la acción de algunas esporas de mohos que tienen en dichos excrementos en putrefacción un óptimo medio de cultivo, y que poseen la propiedad de acentuar sensiblemente la acidez natural de los excrementos mismos.

En la Puerta de los Apóstoles, conocidos y estudiados los distintos recursos técnicos existentes, se decidió adoptar el sistema electrostático que desde hace años se viene aplicando en Italia. Se basa en la distribución, en todos los elementos arquitectónicos y escultóricos que se desea proteger, de una red de líneas que generan impulsos de tensión electrostática

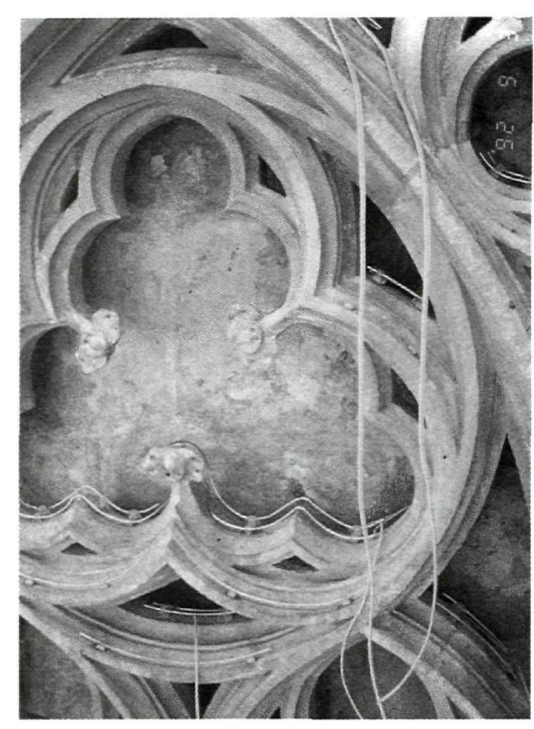

Proceso de montaje, en las ojivas del falso triforio, de conductores y cableado de la instalación electrostática para el alejamiento de palomas.

pura, de cortísima duración y frecuencia aproximada de un impulso por segundo. Estos impulsos son picos de pura tensión sin corriente eléctrica que, por lo tanto, no consumen energía y no provocan daños a personas o animales. Los mismos impulsos crean un campo electrostático alrededor de los conductores que molesta a las palomas alejándolas antes de que puedan llegar a posarse y recibir incluso el impulso. Los conductores son varillas y pletinas de acero inoxidable, conectados entre sí por el necesario cableado, con pequeños aislantes plásticos, que, una vez instalados, han sido mimetizados para disminuir su presencia desde lejos.

La instalación requirió un cuidadoso proceso de adecuación de la disposición de las líneas a la difícil geometría constructiva gótica, debiendo fragmentarse en buen número de pequeños sectores conectados entre sí para garantizar su visualización desde la plaza. Fue utilizado cerca de medio kilómetro de líneas activas, fijadas mediante resinas especiales a los distintos elementos arquitectónicos, y alimentadas por un único generador de impulsos que distribuía éstos a cuatro circuitos independientes.

\section{Ficha Técnica}

Entidades y empresas intervinientes en el Convenio de

Patronazgo: Ayuntamiento de Valencia

Consellería de Cultura de la Generalitat Valenciana Cabildo de la Catedral Metropolitana de Valencia

Dragados y Construcciones, S.A

Bragados Vonsia, S. A

Equipo técnico: Director: Julián Esteban Chapapría, Dr. arquitecto y Jefe del Servicio de Patrimonio Arquitectónico Rafael Soler Verdú, arquitecto colaborado José Manuel Jiménez Espinosa y Soledad Martí Ferrándiz, arquitectos técnicos.
Juan Jesús Gavara Prior, historiador.

Levantamientos planimétricos y delineación asistida por ordena dor: Servicio de Patrimonio Arquitectónico de la Generalitat Valenciana.

Empresas intervenientes: Dragados y Construciones, S.A. C.P.A., S.A.

PROYPINSA, empresa colaboradora

Duración de las obras: marzo de 1991 / noviembre de 1992 